\title{
Pair Sufi symbols in Tatar poetry of the 20th century: complexity and transformation of symbols
}

\section{[Парная суфийская символика в татарской поэзии XX века: усложненность и трансформация символов]}

\author{
Daniya F. Zagidullina - Nurfiya M. Yusupova - Ayrat F. Yusupov
}

\section{DOI: 10.18355/XL.2017.10.03.06}

\begin{abstract}
Аннотация
В данной статье рассматриваются функции и поэтические особенности парных суфийских символов в татарской поэзии начала $\mathrm{XX}$ века. Выявляются релевантные татарской поэзии формы символизации в рамках модернистской художественной парадигмы. В ходе исследования доказывается, что одной из главных отличительных черт национальной поэзии данного периода является усложненность образной структуры и трансформация суфийских символов. Установлено, что парные суфийские символы подвергаются содержательным изменениям, становясь более сложными и непредсказуемыми. Определяется, что в татарских поэтических произведениях наблюдается стилизация парных суфийских символов, обеспечивающая вариативность прочтения поэтических произведений в рамках различных культурных парадигм. Сложные образысимволы одновременно становятся элементом другого, главного символа, наблюдается усложненность, обеспечивающая эффект микротекста в тексте. В данном ключе выявляется поэтическое своеобразие татарской поэзии данного периода.
\end{abstract}

Ключевые слова: татарская поэзия, суфизм, парные символы, поэтика, трансформация

\section{Введение}

Татарская поэзия начала XX века характеризуется появлением на литературной арене необычных для татарской словесности художественных явлений, активным поиском новых средств художественной выразительности. Одним из результатов подобных исканий стало усиление символического мышления, которое по времени совпало с формированием татарской светской литературы. Именно символизм стал для нее художественным ориентиром и философской базой (Zagidullina, 2013b: 40). С одной стороны, в татарской литературе, генетически связанной с культурой арабо-мусульманского Востока, сохранились традиционные механизмы символизации. С другой, дополнение символов различными, в том числе и новыми, значениями привело к трансформации художественной структуры самой татарской литературы, что позволяет говорить «о множественности смысловых пластов в структуре символа» (Yusupova, 2014: 111).

Актуальность данного исследования определяется необходимостью теоретического осмысления той роли, которую сыграли суфийские символы в обновлении поэтической системы татарской поэзии начала $\mathrm{XX}$ века, определения суфийских традиций «изящного» стиля (Sibgatullina, 2000: 31), который имеет свой особый язык, «закодированный в устойчивых суфийских символах» (Zagidullina, 2013a: 115). 
Основные механизмы символизации в татарской поэзии данного периода, трансформация суфийских символов в художественных произведениях в той или иной мере изучены татарскими литературоведами (см.: Zagidullina, 2006, Zagidullina, 2013b; Sayapova, 2006; Yusupova, 2011). Определенные аспекты данного вопроса рассмотрены на материале средневековой суфийской литературы и поэзии Нового времени (см.: Sibgatullina, 2000; Zagidullina, 2007; Yusupova, Yusupov, 2014; Khusnutdinova, Galiullina, Ivanova, Bilalova, Sayfulina, 2015), в рамках изучения лексического состава языка суфийских произведений XIX века (Yusupov, 2015). Однако специальных исследований, посвященных трансформации парных суфийских символов на материале татарской поэзии начала XX века, до сих пор не проводилось.

Широко распространенный в мусульманской общественнофилософской жизни суфизм наполняет и обогащает художественную литературу мистическим содержанием, своеобразным одухотворенным мировосприятием, образами-символами, окутанными таинственностью и скрытым смыслом. Символическое мышление. в целом, является превалирующей тенденцией в суфийской философско-эстетической мысли.

Татарская поэзия начиная, со средних веков и до второй половины XIX века, отличается масштабностью использования суфийской символики. Суфизм влияет на татарскую поэзию, определяя «особенности развития литератур Поволжского региона» (Galimullin, Galimullina, Mingazova, 2014: 249) в целом. Существует мнение, что становление тюрко-татарской религиознодидактической поэзии в Поволжье изначально было напрямую связано с суфизмом, и это влияние сохранилось до середины XIX в. (Кул Шариф, Мауля Колый, Абельманих Каргалый, Шамседдин Заки и др.) (Idiyatullina, 2001: 9). Поэты выстраивают символическую образную систему, выражающую суфийское миропонимание лирического героя; используя символ как основу для передачи авторской позиции и своих философских воззрений.

И в начале XX века татарские поэты продолжают активно использовать эстетические возможности символизации суфийской поэзии. Вопервых, это было продолжением традиций средневековой восточной литературы, сохранившихся, несмотря на активизацию диалога с русской и европейской литературами. Во-вторых, в татарской поэзии начала XX века суфийские культурные коды, в первую очередь, присутствуют как трансформированные устойчивые символы, несущие светское содержание.

Ученые считают, что суфийские символы «растворяются» в романтизме возрожденческих литератур (Stepanyanc, 1987: 68). Данная мысль утверждается и на материале татарской поэзии начала XX века.

\begin{abstract}
Методика
Методологической основой данного исследования является герменевтический подход, который позволяет определить поэтические особенности и семантическое поле парных суфийских символов в художественном тексте. Он направляет рецептивную деятельность читателя на осмысление принципов и приемов изображения, художественных форм освоения действительности, типологических сходств и своеобразия художественных поисков. В данном ключе выявляется поэтическое своеобразие парных суфийских символов. Таким образом, используя герменевтический подход, мы предполагаем проникнуть в особенность функционирования суфийских символов и проследить трансформационные процессы на материале лирических произведений.
\end{abstract}

Кроме того, предполагается использование системно-структурного метода. Системно-структурный подход дает возможность выявить в структуре 
текста два пласта: 1) явный, или «поверхностный» и 2) неявный, или «глубинный», собственно структурный (Bart, 1994).

\section{Трансформация и усложненность парных суфийских символов}

$\mathrm{B}$ татарской поэзии начала XX века активное использование суфийских символов не только в символистских, но и в романтических произведениях становится определенной тенденцией. В подобном ключе суфийская поэзия становится основой символического мышления. Об этом, в частности, на примере творчества Дэрдменда пишет А.М. Саяпова, полагая, что именно «суфийская символика становится исходной точкой мышления поэта» (Sayapova, 2006: 74-75). В татарской поэзии начала XX века суфийские символы, с одной стороны, передают мистическое содержание, с другой стороны, трансформируются и обретают «светское» содержание, начинают служить основным средством изложения философской концепции, оценки жизни и бытия. В поэтических текстах активно используются парные суфийские символы и предстают в роли структурообразующего компонента.

В символическом пространстве поэтических произведений Дэрдменда превалируют такие парные суфийские символы, как «цветок / соловей». В творчестве поэта наблюдается постоянное обращение к образной и интонационной системе суфийской поэзии: суфийские символы и мотивы становятся предметом стилизации и своеобразными кодами данного типа культуры, определяющими двуплановость содержания стихотворений; элементы недосказанности, мистицизма включаются в систему философского знания. Возникает особая поэтика интеллектуально усложненных и эстетически утонченных стихотворений (Zagidullina, 2013b: 45). Данная тенденция утверждается на примере парных символов «цветка / соловья».

Так, в стихотворении «Поэту» Дэрдменд обращается к парной символике «цветок / соловей», которая объединяет два культурных пласта в одно целое и дает возможность двоякого прочтения их на стыке суфийской и восточно-романтической эстетик. В восточном, «светском» контексте цветок символизирует девушку, женскую красоту, а соловей обозначает поэта, творца. В данном ракурсе стихотворение наполняется земной идеей: поэт должен воспевать женскую красоту и быть «соловьем» для «настоящих цветов» в «саду любви». Таким образом, пласт восточных романтических образов включает в картину мира земную любовь.

В суфийском контексте цветок трактуется как Бог, а соловей символизирует суфия, вставшего на Путь к Богу. Посредством парных суфийских образов-символов Дэрдменд воссоздает идею единства макрокосмоса и микрокосмоса. На фоне суфийской картины мира произведение наполняется еще одной идеей: только умеющий отличать истину от лжи, справедливый и имеющий чистую душу человек может приблизиться к Богу: «Не ошибись, эй, соловей, / Умей распознавать - где роза, где репей, / И если в языке - вражды и злобы жало, / Не будет роза никогда твоей» (Dərdemənd, 1999: 52).Таким образом, подобный синтез нескольких культурных пластов в структуре символа становится одним из факторов, способствовавших возникновению усложненности в поэтике символа.

В стихотворении «Лето прошло...» Дэрдменд также обращается к двусоставной суфийской символике «Цветок / соловей». Природа в ее космических проявлениях (лето, осень, солнце, снег и дождь) и в ее частностях (долина, стебель, лед, иголка) воплощает представление о жизни человека как о «живом, разнообразном, движущемся целом. Каждый из образов семантически эквивалентен другому и вносит в кумулятивную цепочку свои смысловые

XLinguae Journal, Volume 10 Issue 3, June 2017, ISSN 1337-8384 
оттенки» (Zagidullina, Amineva, 2016: 140). В традиционно восточном прочтении поэт представляет земную любовь как силу, способную привести жизнь к гармонии. В данном ракурсе парный символ обозначает лирического героя, потерявшего любовь и возлюбленную. По мнению поэта, от потери земной любви и молодости в душе человека остаются лишь боль, обиды и горечь.

В традиционно суфийском прочтении цветок обозначает Бога, а соловей - суфия, посвятившего себя Богу, и идея наполняется религиозным содержанием. Причиной душевной боли, обиды и горечи теперь уже выступает потеря божественной любви, веры вообще.

В татарской поэзии начала XX века чаще всего используются парные символические образы «бабочки /свечи». Так, в стихотворении «Хаят» в описании мотива любви Дэрдменд обращается к распространенным в арабомусульманской эстетике парным символическим образам бабочки и свечи.В структуре текста синтезируются три пласта содержания: «рационалистический, эстетический и мистический, которые выражают три разных типа мировоззрения, основанных на различных видах познания», «где в первой части стиха поэт говорит на языке рационалистической философемы, во второй те же проблемы находят выражение в эстетической и мистической философемах поэта» (Sayapova, 2006: 75). Генетически восходящие к суфийским традициям двусоставные символы в структуре текста обретают статус эстетической и мистической философем.

Образ мотылька, «летящего на огонь и в нем сгорающего, является распространенным в восточной, в первую очередь, персоязычной лирике (Саади, Хафиз)» (Sayapova, 2006: 77). Как известно, образ свечи воспринимается суфиями как божественный свет, Макрокосмос, Абсолют, а образ бабочки символизирует суфия, стремящегося к Богу. Как утверждает Т. Панфилова, образ мотылька «в суфийской поэзии обладает устоявшимся значением: им выражается стремление к познанию» (Panfilova, 1991: 52). Бабочка подлетает к Свече, зажигает огонь в душе и, сгорев, уходит в Небытие. При помощи суфийских символов Дэрдменд представляет движение мира «как движение любви» (Sayapova, 2006: 77), как движение к познанию. Так при помощи закодированного образа поэт формулирует свою философско-эстетическую концепцию - концепцию слияния с Богом: «Бабочка, летающая вокруг огня. / Сгорев в пламени любви, уйдет в вечность» (Dərdemənd, 1999: 57).

Эти же парные суфийские символы используются в романтических произведениях Г.Тукая. Стихотворения «О, это любовь!» (1906), «Ради любви Аллаха» (1906), «После расставания» (1906), «Ужель не полюбишь?» (1906) и др. написаны с использованием суфийской символики. Например, в стихотворении «О, это любовь!» (1906) многозначность таких суфийских символов, как красивая девушка, прекрасное лицо, мотылек, огонь, вино, обеспечивая мерцание в структуре религиозно-суфийских и восточных культурных знаков, дает возможность прочтения текстов в религиозносуфийском и светском контекстах. Говоря словами Р. Ганиевой, стихотворение можно интерпретировать в трех направлениях - собственно суфийском, в духе философии земной любви или концепции литературного творчества (Ganieva, 2002: 9).

В стихотворении Тукай обращается к парным символам «мотылек / огонь», к мотиву опьянения и кружения. Несмотря на отсутствие в тексте образа свечи, она явственно присутствует благодаря образу огня: «Хоть я бедняк, но пожелай - тебе я душу подарю. / Приди, и я, как мотылек, в твоем огне сгорю, сгорю... / Как высшей милости прошу: моя красавица, приди!./ С улыбкой ласковой в глаза мне погляди, о погляди!)» (Пер. В.Тушновой) (Tukaj, 1988: 57).

В восточных литературах мотылек символизирует влюбленную душу, символика огня становится выражением любви, мотивы кружения и опьянения 
направляются на раскрытие земной любви: «Приди, красавица, приди, улыбнись, пожалуйста / Хочу кружиться и кружиться я вокруг тебя» (Tukaj, 1988: 57). Лирический герой становится носителем земной любви к возлюбленной и стремящимся к Аллаху душой. Поэт констатирует, что любовь приносит душе счастье, радость, «которая согревает до самой смерти». Любовь к возлюбленной предстает источником душевной гармонии.

Однако присутствие традиционной суфийской символики и мотивов позволяет увидеть и субъективный, скрытый смысл. В суфийской философии и практике есть ритуал кружения, в процессе которого человек входит в транс. Образы бабочки и свечи в суфийском прочтении символизируют Бога и влюбленного в него суфия, эта картина описывает момент слияния человека с Богом. Лирический герой предстает в роли суфия, влюбленного в Бога и стремящегося к Нему. Любовь к Богу воспринимается как источник душевной гармонии.

С трансформацией символа свечи мы встречаемся в стихотворении С.Рамиева «Обманутый», где суфийский подтекст отсутствует, свеча интерпретируется только в контексте европейской эстетической мысли. В данном ключе она символизирует возлюбленную поэта: «Я говорю об огне любви, / А она зажигает свечу расставанья». Лирический герой выступает в роли любящего, и земная любовь воспринимается как источник душевной гармонии человека.

Подобная символика прослеживается и в отдельных произведениях, посвященных Тукаю, в которых наблюдается устойчивая тенденция $к$ изображению поэта как поэта-пророка. Так, в стихотворении «Почему же гаснут свечи» Х.Габидов обращается к символике «свеча и корабль». В суфийском контексте образ свечи прочитывается как божественный свет, Макрокосм, Абсолют, а корабль символизирует судьбу, одиночество, трагическую участь человека, брошенного в хаос жизни. Но в рамках стихотворения образ свечи, имеющий суфийский подтекст, трансформируется и воспринимается Габидовым как символ высшей божественной силы, одаривающей творческим вдохновением. Образ корабля интерпретирует трагическую судьбу творческой личности. Последние строки рождают чувство горечи, что усиливает эмоциональное воздействие внутренних переживаний лирического «я», подводя к границам скорби, свойственной романтической трагедии.

В романтических стихах Дэрдменда концепция любви воплощается также в парной символике образов «звезда - луна», являющихся в суфийской поэзии символами божественной любви. Например, в стихотворении «Разве сравнится звёздочка с полной луной...» символические образы звезды и луны прочитываются на стыке традиционной восточной и суфийской эстетик. В суфийском контексте «луна-красавица» символизирует Бога, а стремящаяся к луне звезда обладает устоявшимся значением: влюбленный в Аллаха суфий. В данном пласте символические образы луны и звезды служат для передачи концепции единства. Распространенные в арабо-мусульманской литературе символы участвуют в констатации закона бытия.

Кроме того, в восточном романтическом контексте луна воспринимается как девушка-красавица, а звезда - влюбленный в неё юноша. Так возникает еще одна вариация любви: добиться ответного чувства прекрасной девушки можно не мольбами, а только нежной любовью.

В стихотворении Дэрдменда «Мы» (1908) осознание лирическим героем смысла жизни описывается при помощи суфийских символов. С одной стороны, символические и аллегорические образы: страна, караван, высохшие кости, ветер, песок, след, странник, огонь - прочитываются в экзистенциальном

XLinguae Journal, Volume 10 Issue 3, June 2017, ISSN 1337-8384 
плане. В структуре текста ключевые слова произведения сгруппированы вокруг четырех центральных категорий экзистенциализма: бренность земной жизни; течение времени; утрата и смерть; раскаяние. Символические образы-детали констатируют мысль Дэрдменда о смысле жизни: человек ниспослан на землю лишь странником, по истечении времени жизнь заканчивается смертью, и эта смерть, бесследное исчезновение вызывает сожаление. Так поэт констатирует философию стенания: «Дуют ветры, кочуют пески... исчезает след... / Скорбная душа, и мы исчезнем с тобой» (Dərdemənd, 1999: 21). При этом лирический герой выступает в роли человека, осознавшего конечность бытия и неизбежность смерти.

Эти же символы дают возможность прочитать стихотворение в рамках суфийской эстетики. Символ ветра, лежащий в основе данного стихотворения, на Востоке воспринимается как посланец Бога, Судьбы, песок символизирует исчезновение и течение времени, и подразумевает течение вечного времени, движение Космоса. Как известно, в суфийской поэзии на пути познания мира существует четыре элемента - вода, огонь, земля, небо, представляющие собой четыре замкнутых круга и являющиеся часто употребляемыми символами, которые дают возможность объяснить суфиям, как человек приходит в мир и переходит в другую жизнь (Bertel's, 1997: 20). Исходя из этого, можно предположить, что символ огня дает возможность увидеть в жизни человека темные стороны, и в стихотворении возникает другая идея: человек в этом мире - прохожий, «он сам сжигает всякие надежды, сам уходит из жизни, глотая ее огонь» (Zagidullina, 2013b: 69). Человек уходит из жизни, сгорая в «огне», зажженном от чувства раскаяния в содеянном.

\section{Заключение}

$\mathrm{B}$ татарской поэзии начала XX века продолжают широко применяться парные суфийские символы, наблюдается стилизация парных суфийских символов, обеспечивающая вариативность прочтения текстов. Поэты выстраивают символическую образную систему, выражающую суфийское миропонимание лирического героя; трансформируя, используют эти образы для передачи светской идеи и своих философских воззрений.

В результате стилизации суфийской символики появляется возможность двоякой интерпретации текста. Сложные образы-символы одновременно становятся элементами другого, главного символа. Так возникает усложненность символа в рамках произведения, обеспечивающая микротекст в тексте. Микротекст в тексте позволяет интерпретировать стихотворение в контексте восточной, суфийской и европейской эстетики.

Парные суфийские символы, восходящие к суфийской поэзии, подвергаются содержательным трансформациям, становясь более сложными и непредсказуемыми. Усложненность и трансформация суфийских символов становится одной из главных особенностей национальной поэзии данного периода.

На примере лирических произведений Дэрдменда, Г.Тукая, С.Рамиева можно констатировать, что двусоставные символы, прежде всего, используются в любовной лирике. В таких произведениях суфийская символика дает возможность истолковать земную любовь как нечто божественное и сокровенное.

\section{Выводы}

Использование в татарской поэзии начала XX века парных суфийских символов характеризуется следующими особенностями:

1. В татарской поэзии наблюдается содержательная трансформация суфийских символов. 
- Микротекст в тексте обеспечивает усложненность символа, что является одной из главных черт татарской поэзии данного периода.

- Парные суфийские символы активно используются в любовной лирике и дают возможность объяснять земную любовь как нечто божественное и сокровенное.

2. Структура символа характеризуется синтезом различных культурных пластов.

3. Стилизация парных суфийских символов обеспечивает вариативность прочтения поэтических произведений. Двусоставные символы, с одной стороны, дают возможность интерпретировать их в суфийском контексте, с другой стороны - в контексте восточной или европейской эстетики.

\section{Bibliograpic references}

BART, R. 1994. Izbrannye raboty: Semiotika. Poetika / per. s fr. / Sost., obshch. red. i vstup. st. G. K. Kosikova. M.: Progress. Univers. 615 p. ISBN 5-01-004408-0.

BERTEL'S, A. E. 1997. Hudozhestvennyj obraz v iskusstve Irana IX-XV vekov (Slovo, izobrazhenie). M.: Izdatel'skaya firma "Vostochnaya literatura" RAN. 422 p. ISBN 5-02-017707-5.

Dərdemənd. Agargan kyl = Posedevshaya struna: SHigyr'lər / Tez. həm keresh syz avt. R. Haris; Fən. red. N. Hisamov. Kazan: Məgarif, 1999. 111 p. ISBN 5-77610833-0.

GANIEVA, R. K. 2002. SHagyjr'neң ruhi den'yasy. Kazan. 111 p. Na tatarskom iazyke. ISBN 5-94113-104-6.

GALIMULlin, F. G. - GALIMULlinA, A. F. - MINGAZOVA, L. I. 2014. The development of the literatures of the people of the Volga region in multi-ethnic Russia. Journal of Language and Literature, n. 5(3), pp. 248-252. ISSN: 2078-0303.

IDIYATULLINA, G. G. 2001. Abu Nasr Kursavi i sredneaziatskie istoki tatarskoj obshchestvennoj mysli konca XVIII - nachala XIX veka (po materialam traktata «Alirshad li-l-‘ibad»). Avtoref. ... kand. ist. nauk. Kazan'. 22 p.

KHUSNUTDINOVA, L. G. - GALIULLINA, S. D. - IVANOVA, O. M. BILALOVA, L. M. - SAYFULINA, F. S. 2015. An Ideal World in the Medieval sufi Literature of Siberian Tatars. Mediterranean Journal of Social Sciences, vol. 6, Is. 3S4, pp. 207-212. ISSN: 2039-9340.

PANFILOVA, T. V. 1991. CHelovek v mirovozzrenii Vostoka. M.: Znanie. 64 p. ISBN 5-07-001931-7.

SAYAPOVA, A. M. 2006. Dehrdmend i problema simvolizma v tatarskoj literature. Kazan': «Alma-Lit». 246 p. ISBN 5-87-730-100-7.

SIBGATULLINA, A. T. 2000. Sufizm v tatarskoj literature (istoki, tematika i zhanrovye osobennosti): Avtoref. ... d-ra filol. nauk. Kazan'. 62 p.

STEPANYANC, M. T. 1987. Filosofskie aspekty sufizma. M.: Nauka. 192 p.

TUKAJ, G. 1988. Stihotvoreniya i poehmy. M.: «Sovetskij pisatel'». Leningradskoe otdelenie. 457 p. ISBN 5-265-00269-3.

YUSUPOV, A. F. 2015. Specifics of Sufi and Islamic terminology use in the poetry of the XIXth century. European Journal of Science and Theology, Vol. 11, No. 5, pp. 275-284. ISSN 1841-0464.

YUSUPOVA, N. M. 2011. XX gasyr tatar shig"riyatendə simvollar. Kazan: Kazan un-ty. 118 p. Na tatarskom iazyke. ISBN 978-5-98180-904-0.

YUSUPOVA, N. M. 2014. Simvolizaciya v tatarskoj poehzii nachala XX veka. Vestnik Udmurtskogo universiteta. Seriya «Istoriya i filologiya», No. 4, pp. 111-114. ISSN 2412-9534. 
YUSUPOVA, N. M. - YUSUPOV, A. F. 2014. Tatar sufi poetry of the XVI-XIX centuries: peculiarities, world models and symbolics. Life Science Journal, 11(11), pp. 598-601. ISSN 1097-8135.

ZAGIDULlinA, D. F. 2006. Den'ya syrəte yzgəry. Kazan: Məgarif. 146 p. Na tatarskom iazyke. ISBN 5-7761-1619-8.

ZAGIDULLINA, D. F. 2007. Kartina mira i hudozhestvennye osobennosti srednevekovoj tatarskoj sufijskoj poehzii. Uchenye zapiski Kazanskogo gosudarstvennogo universiteta, n. 2, T. 149. Seriya gumanitarnyh nauk, pp. 206-216. ISSN 1815-6126.

ZAGIDULLINA, D. F. 2013a. Allegori in tatar literature as a manifestation of ethnic features in text. TATARICA, n.1, pp. 115-126. ISSN 2311-2042.

ZAGIDULLINA, D. F. 2013b. Modernizm v tatarskoj literature pervoj treti XX veka. Kazan: Tat. knizh. izd-vo. 207 p. ISBN 978-5-298-02500-3.

ZAGIDULLINA, D. F. - AMINEVA, V. R. 2016. Avant-Garde Research in the Field of Verse Forms (based on I. Yuzeev lyrics). XLinguae European Scientific Language Journal, vol. 9, issue 1, pp. 135-145. ISSN 1337-8384.

The work is performed according to the Russian Government Program of Competitive Growth of Kazan Federal University.

\section{Words: 3114}

Characters: 24560 (13,64 standart pages)

Prof., academician Daniya F. Zagidullina, Doctor of Philology,

Academy of Sciences of the Republic of Tatarstan

Bauman st., 20. 420111 Kazan,

Republic of Tatarstan, Russian Federation

zagik63@mail.ru

Associate Professor Yusupova Nurfiya Marsovna, Candidate of Philology,

Department of Tatar Literature

Kazan Federal University

Kremlyovskaya st., 18. 420008 Kazan

Republic of Tatarstan, Russian Federation

faikovich@mail.ru

Associate Professor Yusupov Ayrat Faikovich, Candidate of Philology,

Department of Tatar linguistics

Kazan Federal University

Kremlyovskaya st., 18. 420008 Kazan

Republic of Tatarstan, Russian Federation

faikovich@mail.ru 